\title{
Microstructural Characterization and Evaluation of the Thermomechanical Behavior of an Al 7075-T651 Alloy Deformed by Two Passes of ECAP
}

\author{
Daniel Carvalho Silva ${ }^{a}$, Mônica C. Rezende ${ }^{a}$, Neil de Medeiros ${ }^{a *}$ \\ aPrograma de Pós-graduação em Engenharia Metalúrgica, Universidade Federal Fluminense, 27255- \\ 125, Volta Redonda, RJ, Brazil
}

Received: December 08, 2016; Revised: September 19, 2017; Accepted: October 18, 2017

\begin{abstract}
Billets of an A1 7075-T651 alloy were processed by two passes of equal channel angular pressing, ECAP, by following route A. First pass was performed at $180^{\circ} \mathrm{C}$ and the second one in the temperatures 130 and $180^{\circ} \mathrm{C}$. The resulting microstructures were characterized by optical microscopy, OM, and scanning electron microscopy, SEM. Also, material macroscopic mechanical properties were evaluated by performing uniaxial compression and Vickers microhardness tests. After the second pass, it was not verified a noticeable grain refinement. After second pass at $130^{\circ} \mathrm{C}$, the samples presented higher mechanical strength than observed after their processing at $180^{\circ} \mathrm{C}$ and the second pass resulted in a decrease in the mechanical properties compared to the deformation by one pass at $180^{\circ} \mathrm{C}$.
\end{abstract}

Keywords: Equal channel angular pressing, thermal treatments, microstructural characterization, thermomechanical behavior, Al 7075-T651 alloy.

\section{Introduction}

The materials are the basis of any civilization and the development of new technologies, fundamental for human evolution, are made possible by science and engineering that seek incessantly to improve the properties of these materials. These improvements make it possible to increase the field of application and in some cases make possible new uses that until today were not possible. Within this context the methods of Severe Plastic Deformation, SPD, are investigated, because they are able to improve the properties of the processed materials.

One of the most widespread techniques among SPD methods is the ECAP technique, where the material is pressed through a die composed of two equal-sized channels that intersect each other at an angle, $\Phi$, and additional angle $\Psi$, which defines the arc of curvature of the outer intersection of the channels, causing the material to be subjected to the simple shear stress in the intersection plane ${ }^{1,2}$.

The main advantage of the ECAP process is preservation of the cross-sectional dimension after processing, thus making it possible to perform repeated deformations until they accumulate at high levels. With this, slip systems can be activated at each pass through the rotation of the samples at the different angles associated with each route. In addition to improving the mechanical properties, produce extremely fine grains and a variety of textures ${ }^{3,4}$.

The Al 7075-T651 aeronautical alloy investigated in this work has an excellent balance of properties required in this industry, such as high mechanical strength, moderate fracture toughness and corrosion resistance ${ }^{5}$. It is of great interest to investigate whether the increase in mechanical strength observed in ECAP processed alloys can be added to the increased strength promoted by the aging effect in $\mathrm{Al}$ 7075 alloy. Aged hardenable alloys are generally difficult to process by ECAP at room temperature because they invariably fail by catastrophic cracks or segmentation ${ }^{6}$. The aim of the work was to evaluate the thermo-mechanical and microstructural behavior of this alloy processed by ECAP by distinct conditions, that is, as-received, after first pass at $180^{\circ} \mathrm{C}$ and after second pass either at $130^{\circ} \mathrm{C}$ or $180^{\circ} \mathrm{C}$, by assuming route $\mathrm{A}$. The microstructural characterization was performed using optical microscope, OM, scanning electron microscope, SEM, and energy dispersive spectroscopy, EDS. The material mechanical behavior was evaluated by performing Vickers hardness and uniaxial compression tests after each deformation pass.

This process can be driven by four different routes: A, $B_{A}, B_{C}$ and $C$. On the route $A$, investigated in this study, there is no rotation of the sample between the deformation passes causing the material distortion to be continuously increased after each pass providing refined and elongated grains in comparison to starting material. On the other hand and after each pass, in the route $B_{A}$ the workpiece is rotated by $90^{\circ}$ in alternate directions while for the route $\mathrm{B}_{\mathrm{C}}$ these rotations occur at $90^{\circ}$ in the same sense (clockwise or counterclockwise). In addition, in the case of route $\mathrm{C}$, samples are rotated by $180^{\circ}$. Routes $\mathrm{B}$ and $\mathrm{C}$ were not investigated in the present work.

\section{Experimental Procedures}

The experiments were carried out using the $\mathrm{Al} 7075$ T651 alloy, whose chemical composition, obtained by means 
of the Oxford Instruments model Foundry Master Pro, is presented in Table 1.

The material was received as a plate with $1000 \times 1000 \times 20 \mathrm{~mm}$. The material was machined in the form of solid square section billets with $9.8 \mathrm{~mm}$ of edge and $40 \mathrm{~mm}$ of length for ECAP processing, $5 \mathrm{~mm}$ of which is milled at the top and bottom of its thickness. The material for the compression tests was machined with the same section, but $20 \mathrm{~mm}$ in length.

The samples were prepared for OM observation by means of conventional metallography techniques, subjected to successive grinding, with 500, 1200 and final 2500 granulation sands using running water as a lubricant. After this step they were electrolytically polished with a solution of $59 \% \mathrm{CH}_{4} \mathrm{O}$, $35 \% \mathrm{C}_{2} \mathrm{H}_{4}(\mathrm{OH})_{2}$ and $6 \% \mathrm{HClO}_{4}$ (in volume). The potential difference applied was $16 \mathrm{~V}$ for $25 \mathrm{~s}$, at room temperature, using a Power supply (Manufacturer Instrutherm, model DC Power Supply FA-3005). The chemical etch was performed by immersion with a solution composed of $10 \mathrm{ml}$ of HF, 15 $\mathrm{ml} \mathrm{HCl}, 25 \mathrm{ml} \mathrm{HNO}_{3}$ and $50 \mathrm{ml}$ of distilled water known as Keller's reagent for 20 s.

The samples were pressed through a H13 tool steel die with a square section with an area equal to $100 \mathrm{~mm}^{2}$, intercepted at $\Phi=90^{\circ}$ and $\Psi=0^{\circ}$.

The billets were pressed by $\mathrm{H} 13$ tool steel punch 110 $\mathrm{mm}$ in length. Figure 1 shows the schematic drawing of one side of the die with the material positioned to the bottom of the vertical channel.

Optical microscopy was performed on a Nikon Eclipse LV150 reflective light microscope, associated with Nikon DS-Fil camera and NIS-Elements D 3.2 software. To obtain data on the morphology, the samples were submitted to SEM in the Secondary Electrons mode (SE), EVO model MA10 of the manufacturer Zeiss with $\mathrm{LaB}_{6}$ filament with acceleration voltage $10 \mathrm{kV}$. In order to detect the present components, analyzes by dispersive energy spectroscopy, EDS, were obtained using a JEOL- JSM model 6460LV microscope. All the analysis were done on TD x DN plane.

Samples were deformed by ECAP using a universal machine EMIC model 23-600, with a maximum capacity of $600 \mathrm{kN}$. The preparation of the extrusion was first done by lubricating the inner channels of the die with a dry lubricant, the $\mathrm{MoS}_{2}$ base, then with the die still open, the die also lubricated and placed inside the die channel. After the adjustment, the punch was positioned exactly on the specimen, $70 \mathrm{~mm}$ from the top of the die and $40 \mathrm{~mm}$ from the bottom of the vertical channel. The test speed was maintained at $0.5 \mathrm{~mm} / \mathrm{min}$, that is, by assuming a nominal strain rate of $3.33 \cdot 10^{-4} \mathrm{~s}^{-1}$. Each sample was deformed by two pressing passes. The first pass was performed at $180^{\circ} \mathrm{C}$ for all the samples and the second pass, assuming route $\mathrm{A}$, was performed at 130 and $180^{\circ} \mathrm{C}$. These

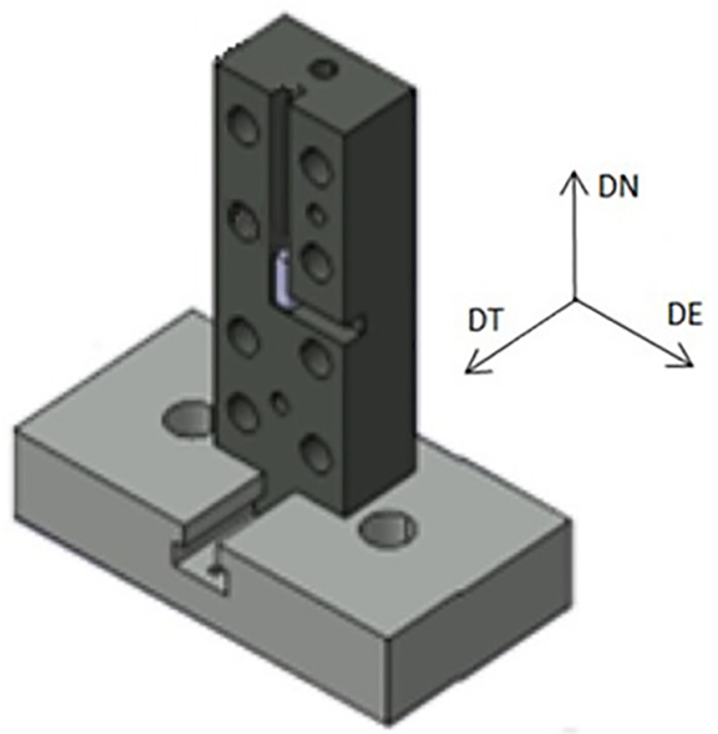

Figure 1. Schematic drawing of the matrix within sample positioned in the vertical channel ${ }^{7}$.

temperatures were measured with a K-type thermocouple placed at the end of workpieces and the temperature control was performed by the on/off method on a circuit breaker connected to two $650 \mathrm{~W}$ tubular resistors placed in the specific openings for them in the ECAP die. The tests were interrupted when the punch reached $35 \mathrm{~mm}$ from the stroke, $5 \mathrm{~mm}$ to the end of the inferior channel.

ECAPed samples Vickers microhardness were measured by performing 16 indentations, with a load of $100 \mathrm{gf}$ and a loading time of $20 \mathrm{~s}$ in the TD x ND plan of the sample with a distance of $1 \mathrm{~mm}$ from the edge, thus neglecting the edge effects. Compression tests were also realized in a universal machine used on ECAP process. These tests were conducted at a constant speed of $0.5 \mathrm{~mm} / \mathrm{min}$. The criteria for stopping the tests were displacement of $15 \mathrm{~mm}$ of the movable (upper) plate. A typical value of $71.7 \mathrm{GPa}$ was adopted for the elastic modulus of Al 7075-T651 alloy. Then, the yield stress, $\sigma_{\mathrm{y}}^{0.2}$, was calculated by offset method. The material plastic parameters, i.e., mechanical strength, $\mathrm{K}$, and hardening exponent, $\mathrm{n}$, were obtained by fitting the nonlinear true stress-strain curves through Hollomon model.

\section{Results and Discussion}

\subsection{Microstructural characterization}

The second pass by ECAP was performed at $130^{\circ} \mathrm{C}$ and $180^{\circ} \mathrm{C}$, due to material low ductility observed at lower temperatures and therefore failed to $\mathrm{crack}^{7,8}$.

Table 1. Chemical composition of alloy Al 7075 (in mass fraction, \%)

\begin{tabular}{cccccccccc}
\hline $\mathrm{Al}$ & $\mathrm{Zn}$ & $\mathrm{Mg}$ & $\mathrm{Cu}$ & $\mathrm{Fe}$ & $\mathrm{Cr}$ & $\mathrm{Si}$ & $\mathrm{Mn}$ & $\mathrm{Ti}$ & Others (total) \\
\hline 90.1 & 5.52 & 2.29 & 1.41 & 0.209 & 0.203 & 0.12 & 0.0473 & 0.0208 & 0.0799 \\
\hline
\end{tabular}


The analysis by optical microscopy in the TD x ND plane is shown in Fig. 2, with a magnification of 100x and etch with Keller reagent for 20s. Fig.2a reveals the microstructure in the starting condition, this being the first pass by ECAP at $180^{\circ} \mathrm{C}$. Figure $2 \mathrm{~b}$ presents the microstructure after the second pass at $130^{\circ} \mathrm{C}$ and Fig. $2 \mathrm{c}$ depicts the microstructure after the second pass at $180^{\circ} \mathrm{C}$. One can observe that there is no significant changes between the as-received material and the second pass at both $130^{\circ} \mathrm{C}$ and $180^{\circ} \mathrm{C}$. It can also be seen that in all the micrographs the grains are elongated as a consequence of the material pre-processing by hot rolling in the as-received condition.

The SEM analysis in the TD $x$ ND plane in the secondary electron mode is shown in Fig. 3, with a magnification of 2000x and etch with Keller reagent for 20s. Fig. 3a displays the microstructure in the as-received condition while Fig. $3 \mathrm{~b}$ presents the microstructure after the second pass at $130^{\circ} \mathrm{C}$. Also, Fig. $3 \mathrm{c}$ reveals the microstructure after the second pass at $180^{\circ} \mathrm{C}$. It can be noted that there were no significant changes between the as-received condition and the second pass at both $130^{\circ} \mathrm{C}$ and $180^{\circ} \mathrm{C}$ as the $\mathrm{OM}$ analysis. In the Fig. $3 \mathrm{~b}$ it is possible to observed inside the red circle the presence of intermetallic phase. As previously discussed, in the images performed through optical microscopy the grains are also elongated in the SEM images, see Fig. 2.
The samples in all the conditions presented points and dark micro regions when analyzed by OM and by SEM in SE mode. These regions were better visualized and analyzed with the compositions performed on EDS analysis. Figures 4a and $4 \mathrm{~b}$ show two distinct regions at different magnifications in the sample TD x ND plane after the first pass at $180^{\circ} \mathrm{C}$. Figures $4 \mathrm{c}$ and $4 \mathrm{f}$ depict the EDS spectra from these evaluated regions. These regions denote insoluble phases and precipitate particles of $\mathrm{Mg}(\mathrm{Zn}, \mathrm{Al}, \mathrm{Cu})_{2}{ }_{2}^{9}$. As could be confirmed on point 1 , see Fig. $4 \mathrm{a}$, and the respective spectrum shown in Fig. $4 \mathrm{c}$, there is a presence of $\mathrm{Mg}$ and $\mathrm{Zn}$, which possibly carry an intermetallic phase of Al-Mg-Zn. Point 2 in Fig. 4b shows the characteristic spectrum of Al-Mg-Cu, as observed in Fig. 4d. Point 3 in Fig. 4b is associated to the spectrum presented in Fig. 4e. Finally, in point 4 it was only noted $\mathrm{Al}-\mathrm{Cu}$ precipitate, as can be observed in the respective spectrum displayed in Fig. 4f.

\subsection{Mechanical properties}

Figure 5 shows the material true stress-strain curves for as-received condition and after two ECAP passes at 130 and $180^{\circ} \mathrm{C}$. The compression tests showed different behaviors according to the condition of the sample tested. As received material and after first pass at $180^{\circ} \mathrm{C}$ it was observed both higher compression limit stress, CLS, yield stress and strength

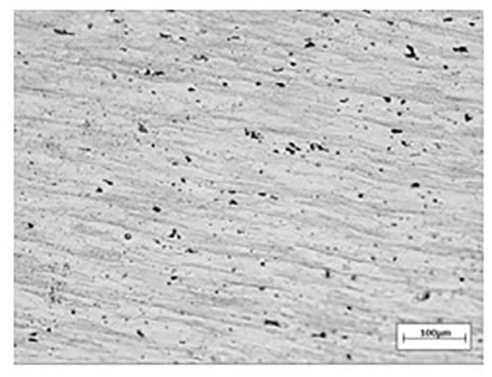

(a)

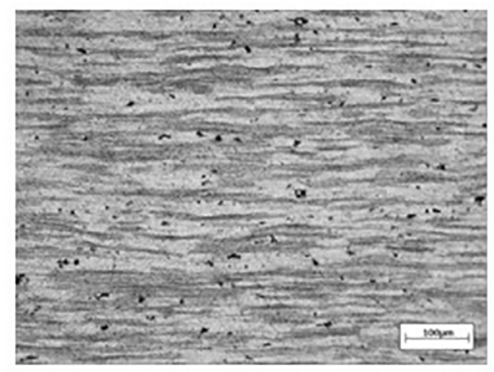

(b)

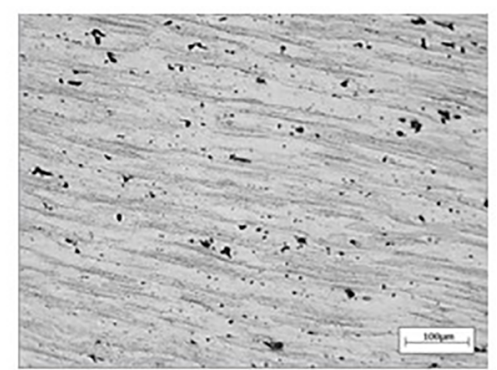

(c)

Figure 2. Microstructure analyzed by optical microscopy 100x magnification in TDxND plane, Keller 20s attack through: a) 1st pass at $\left.180^{\circ} \mathrm{C} \mathrm{b}\right) 2$ nd pass at $\left.130^{\circ} \mathrm{C}, \mathrm{c}\right) 2 \mathrm{nd}$ pass at $180^{\circ} \mathrm{C}$.

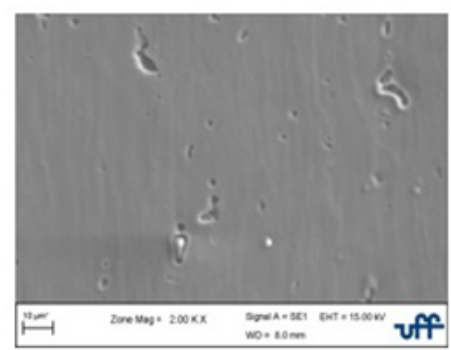

(a)

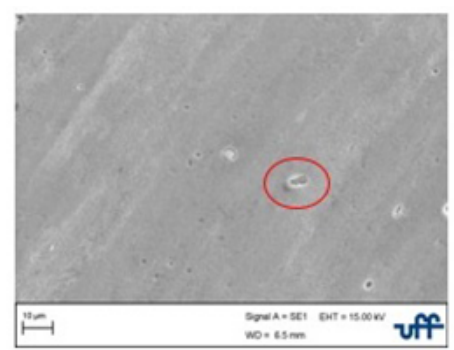

(b)

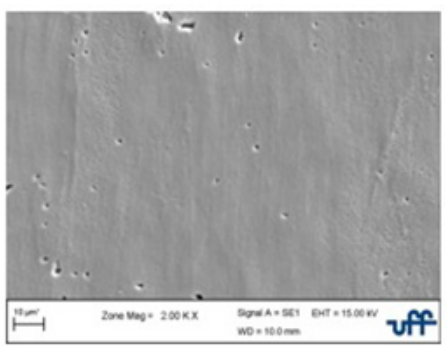

(c)

Figure 3. Microstructure analyzed by $\mathrm{MEV}$, SE mode $2000 \mathrm{x}$ magnification, Keller $20 \mathrm{~s}$ attack: a) $1 \mathrm{st}$ pass at $180^{\circ} \mathrm{C}$ b) $2 \mathrm{nd}$ pass at $130^{\circ} \mathrm{C}$, c) 2 nd pass at $180^{\circ} \mathrm{C}$. 


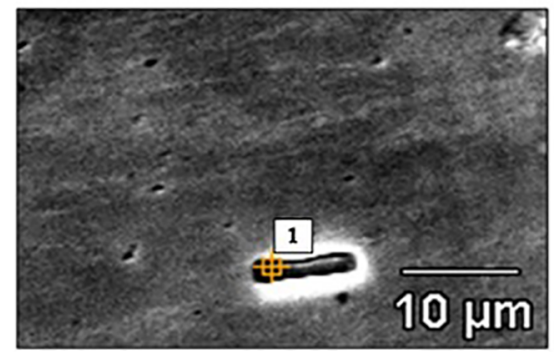

(a)

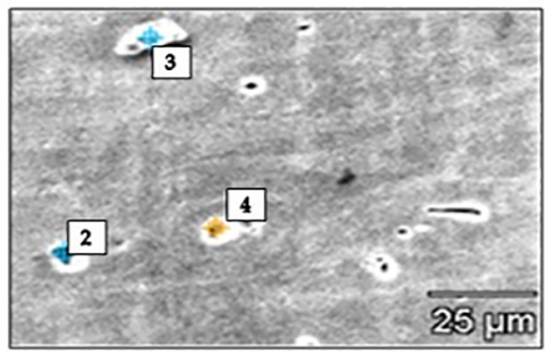

(b)

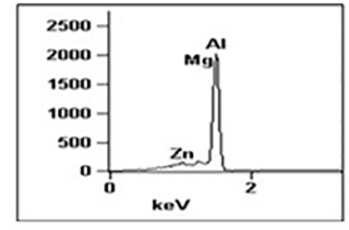

(c)

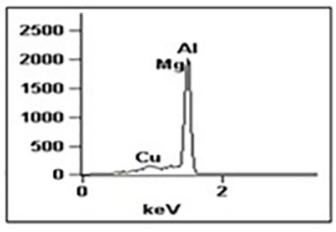

(d)

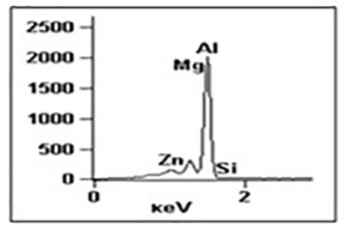

(e)

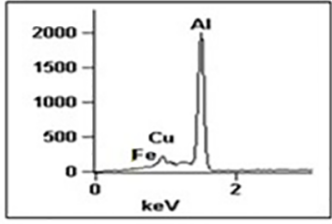

(f)

Figure 4. EDS analysis on start condition after 1 st pass at $180^{\circ} \mathrm{C}$ a) Point 1 ; b) Point 2, 3 and 4; c) Spectrum point 1; d) spectrum point 2 ; e) spectrum point 3 ; f) spectrum point 4.

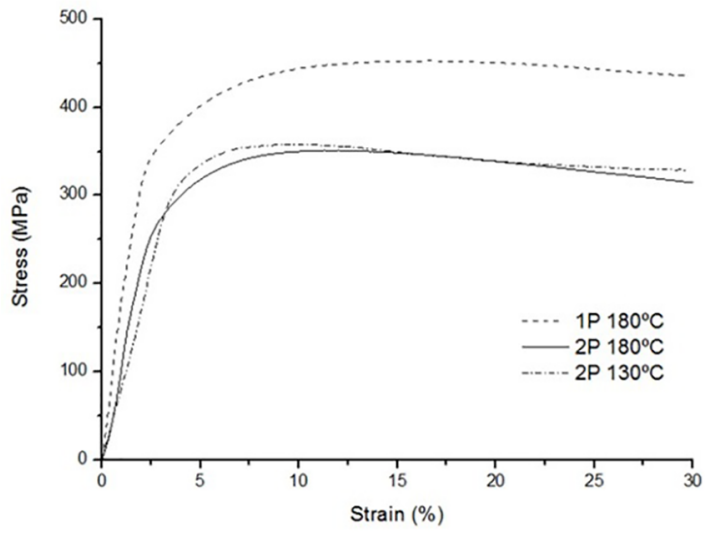

Figure 5. True Stress-strain curve of uniaxial compression test to analyzed conditions. coefficient, $\mathrm{K}$, but the lowest strain hardening exponent, $\mathrm{n}$. The samples after the second pass at 130 and $180^{\circ} \mathrm{C}$ showed similar behaviors in the true stress- strain curve. However, the was observed an increasing of mechanical properties at $130^{\circ} \mathrm{C}$, that is, CLS $2.0 \%$ higher, $\mathrm{K} 4.7 \%$ higher, $\mathrm{n} 9.6 \%$ higher and $\sigma_{\mathrm{y}}^{0.2} 29.4 \%$ higher. These aspects are listed in Table 2.

The Vickers microhardness test differed from the behavior presented in the compression tests after the second pass through route $\mathrm{A}$ at $130^{\circ} \mathrm{C}$ since the latter presented greater resistance to indentation. This resistance was close that obtained in the as-received condition, whereas for the true stress-strain curves one can be observe a great difference in the mechanical properties, i.e., it was higher than after pressing for two passes at $130^{\circ} \mathrm{C}$. The sample deformed by two passes at $180^{\circ} \mathrm{C}$ showed lower indentation resistance,

Table 2. Material mechanical properties.

\begin{tabular}{cccccc}
\hline Test & $\begin{array}{c}\text { Compression limit } \\
\text { stress (MPa) }\end{array}$ & $\mathrm{K}(\mathrm{MPa})$ & $\mathrm{n}$ & \multicolumn{2}{c}{$\begin{array}{c}\text { Vickers } \\
\sigma_{\mathrm{y}}^{0.2}(\mathrm{MPa})\end{array}$} \\
\hline $1 \mathrm{P} 180^{\circ} \mathrm{C}$ & 453 & 588 & 0.155 & 359 & $129.1 \pm 4.7$ \\
microhardness \\
$\left(\mathrm{HV} 130^{\circ} \mathrm{C}\right.$
\end{tabular}


which is consistent with the true stress-strain curve shown in Fig. 5, since this condition provided lower K-values.

The increase of dislocation density attributed to the material during ECAP reaches a saturation point from which the recovery phenomenon stands out on the increase of the mechanical strength and a decreasing in the hardness occurs for more processing passes. It can explain the decreasing in mechanical strength observed from the starting material for the second pass at both 130 and $180^{\circ} \mathrm{C}^{7,8,10,11}$. Another phenomenon that can occur at these temperatures is overaging with precipitates growth and transformation to more stable phases.

\section{Conclusions}

The behavior of Al 7075-T651 alloy processed by two passes of ECAP via route $A$ at 130 and $180^{\circ} \mathrm{C}$ was investigated in terms of microstructure changings and macroscopic mechanical properties. The following conclusions can be outlined:

- No noticeable microstructural changes were observed by evaluation through MO and SEM techniques. It is necessary complementary evaluations by Transmission Electron Microscopy, TEM and Electron Backscatter Diffraction, EBSD, to confirm grain refinement and quantify high angle boundaries fraction;

- The coarse precipitates observed by OM are composed by of Al, $\mathrm{Mg}, \mathrm{Cu}, \mathrm{Zn}$. TEM investigations can be employed to determine morphology and dimensions of precipitates;

- In terms of mechanical behavior, it was observed through stress-strain diagrams and Vickers hardness tests, that the material presented higher strength after single pass at $180^{\circ} \mathrm{C}$. Also, performing the second pass at $130^{\circ} \mathrm{C}$, it was obtained an intermediary resistance. Then, the material lesser hardening capability was achieved after second pass at $180^{\circ} \mathrm{C}$.

\section{Acknowledgments}

The authors are grateful to the School of Engineering and Materials - MetalMat/UFRJ, CAPES, CNPq and FAPERJ for the financial support for the activities inherent in this work. Also, thanks to Prof. Roberto Braga Figueiredo and Prof. Paulo Roberto Cetlin for their help during ECAP tooling designing.

\section{References}

1. Valiev RZ, Langdon TG. Principles of equal-channel angular pressing as a processing tool for grain refinement. Progress in Materials Science. 2006;51(7):881-981.

2. Langdon TG. The principles of grain refinement in equalchannel angular pressing. Materials Science and Engineering: A. 2007;462(1-2):3-11.

3. El-Danaf EA. Mechanical properties, microstructure and texture of single pass equal channel angular pressed 1050, 5083, 6082 and 7010 aluminum alloys with different dies. Materials \& Design. 2011;32(7):3838-3853.

4. Gholinia A, Prangnell PB, Markushev MV. The effect of strain path on the development of deformation structures in severely deformed aluminium alloys processed by ECAE. Acta Materialia. 2000;48(5):1115-1130.

5. Alcoa. ALCOA mill products Alloy 7075 Plate and Sheet. Available from: $<$ http://www.alcoa.com/mill_products/catalog/ pdf/alloy7075techsheet.pdf $>$. Access in: 26/10/2017

6. Cepeda-Jiménez CM, García-Infanta JM, Ruano OA, Carreño C. Mechanical properties at room temperature of an $\mathrm{Al}-\mathrm{Zn}-\mathrm{Mg}$ $\mathrm{Cu}$ alloy processed by equal channel angular pressing. Journal of Alloys and Compounds. 2011;509(35):8649-8656.

7. Victer DD, Figueiredo RB, Cetlin PR, de Medeiros N. Análise do comportamento mecânico da liga A17075-T651 deformada via técnica de prensagem em canais equiangulares. In: Proceedings of the $9^{\circ}$ Congresso Nacional de Engenharia Mecânica (CONEM 2016); 2016 Aug 21-25; Fortaleza, CE, Brazil.

8. Cardoso KR, Travessa DN, Botta WJ, Jorge AM Jr. High Strength AA7050 Al alloy processed by ECAP: Microstructure and mechanical properties. Materials Science and Engineering. A. 2011;528(18):5804-5811.

9. Hatch JE, ed. Aluminum Properties and Physical Mettalurgy. Materials Park: ASM International; 1984. 397 p.

10. García de La Infanta Belío J. Efecto del procesado por extrusión em canal angular constante (ECAP) en la microestructura y las propriedades mecánicas de dos aleaciones de aluminio: Al 7075 y $\mathrm{Al}-7 \% \mathrm{Si}$. [Thesis]. Madrid: Universidad Complutense de Madrid; 2009.

11. Companhoni MVP. Produção e caracterização de zircônio nanocristalino e suas ligas processados por deformação plástica severa e aplicação como biomaterial. [Thesis]. Rio de Janeiro: Instituto Militar de Engenharia; 2012. 